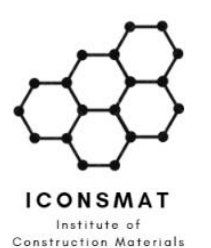

Content list available at ICONSMAT

Journal of Construction Materials

Journal homepage: www.iconsmat.com.au/publication
Article history:

Received 08 November 2020

Received in revised form

15 December 2020

Accepted 18 December 2020

Available online

2 January 2021

\title{
Dynamic data processing for building energy consumption
}

\author{
Farid Sartipi ${ }^{1 *}$ \\ 1* Corresponding author: E: farid.sartipi@iconsmat.com.au; Institute of Construction Materials
}

\begin{abstract}
With the growing attention to smart buildings, local governments are seeking practical ways to optimize the energy consumption of commercial buildings. An ideal smart building is capable of monitoring its own energy consumption and adjusting the operation of electric devices, being lighting and air conditioners, based on the occupant behaviour. In this study, data had been obtained from the monitoring sensors in a commercial building located in the heart of Sydney from 2013 until 2020 on a 15-minute time intervals. The data derivation and analysis are intrinsically static at the moment which makes it difficult for building management to make instantaneous decision regarding the measures to be taken for a lower energy consumption. Using data analysis and visualization tools in Tableau, this study provides detailed insights about the trends in energy consumption in the given building. The outcomes facilitate the decision making for building management and can be seen as a milestone towards a dynamic optimization protocol in a bigger picture which is introduced in the second part of this study.
\end{abstract}

DOI: 10.36756/JCM.v2.2.4 (C2021 Institute of Construction Materials

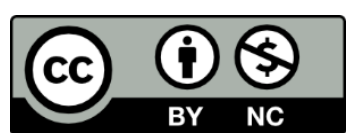

\section{Keywords}

Smart building; Energy consumption; Data analysis; 3D printing 


\section{Introduction}

Occupant behaviour is known as one of the most important factors in building energy consumption that can be controlled. Other factors such as the quality of building insulating panels and window-to-wall ratio are also considered important, but they cannot be changed. It is because of this reason that the buildings services and facility managements are interested in gaining more control over the occupant behaviour in order to reduce the energy consumption which will then ultimately results in conservation of natural resources in the context of smart sustainable cities [1]. The household characteristics, in fact, such as life style, cognitive variables, and perception of comfort are some of the determinants for the level of energy consumption [2].

The Australian government Department of Climate Change and Energy Efficiency had reported an estimate of commercial buildings energy consumption across the country [3]. In this report, the energy related data is obtained from 388 individual buildings occupied by universities across the country. The energy consumption is typically calculated per square meter of land occupied. Melbourne stands in the first place for the highest area of land in Australia occupied by universities and it is followed by Sydney in the second place. Therefore, a slight decrease (or optimization) in energy consumption of buildings in these two capital cities can result in huge benefits for development in regional areas. The majority of building energy consumption in Australian universities is derived from Heating, Ventilation, and Air Conditioning (HVAC) by $50 \%$ of the total, and by $18 \%$ of the total from Lighting [3]. So, if it is ought to minimize the building energy consumption, then it is rational to put efforts in reducing the level of energy consumption by HVAC and lighting, which is in fact subject to this study. To achieve this goal, the concept of smart buildings is adopted herein.

The idea of smart cities and buildings is not separate from digital technologies. In fact, it is the integration of digital technologies with the urban texture which gives meaning to smart buildings. Many researchers had studied this idea from various perspectives. Some propose Al based prediction model $[1,4,5]$, some energy dashboard [6], others design an loT communication platform [7], yet all of the proposals are categorized as a form of digital innovation. The end users of these smart energy saving technologies are typically facility managements, strata managements, building management, etc., as the system enables a platform for information sharing [8]. Examples of smart control systems are promising. Reports indicate that energy saving is achieved from $10 \%$ for simple controls and up to $60 \%$ for more advanced systems [9].

In this study, data related to environmental variables inside a commercial building located in Sydney had been obtained. The data sheet includes energy consumption in the unit of W.h recorded in 15 minutes time intervals for a period of 8 years since 2013 adding up to 260,419 different rows of data. Using Tableau ${ }^{\circledast}$ in the first part of this study, the given data sheet is analysed and interpreted in a static fashion. The impact of COVID19 in 2020 is notable. The static data analysis intrinsically has some limitations compared to a dynamic method of analysis. It is time consuming. Data output is generated with a delay for up to months in some cases, and it does not allow the end user to make instantaneous decisions. Altogether are seen as the motive to design a dynamic data processing and visualization protocol in the second part of this study. 


\section{Tertiary education building}

Australian Department of Climate Change and Energy Efficiency in 2012 had published a comprehensive report on the buildings energy consumptions across the whole continent [3]. In this report, a commonly used metric is defined as Usable Floor Area (UFA) which indicates the area under which teaching, research and support activities are directly undertaken. It is important to conserve this definition in future studies to achieve a comparable longitudinal outcome. The report projects an estimation of University floor area in different cities between 1999 and 2020. The university sector in total expands over an area of 12,047,000 $\mathrm{m}^{2}$ with Melbourne and Sydney leading in the first and second positions in the table respectively in terms of area occupied by universities. In Sydney the UFA had increased by $120 \%$ in a 20 years period meanwhile the increase in UFA in Melbourne had recorded $134 \%$ in the same period. The data presented in table 2 had been derived from 17 university campuses across the continent.

In terms of energy intensity, the same report had obtained relevant data from 388 individual buildings occupied by universities. Between 2001 and 2011 the national average energy intensity of university buildings had risen modestly from $780 \mathrm{MJ} / \mathrm{m}^{2}$ to $869 \mathrm{MJ} / \mathrm{m}^{2}$.

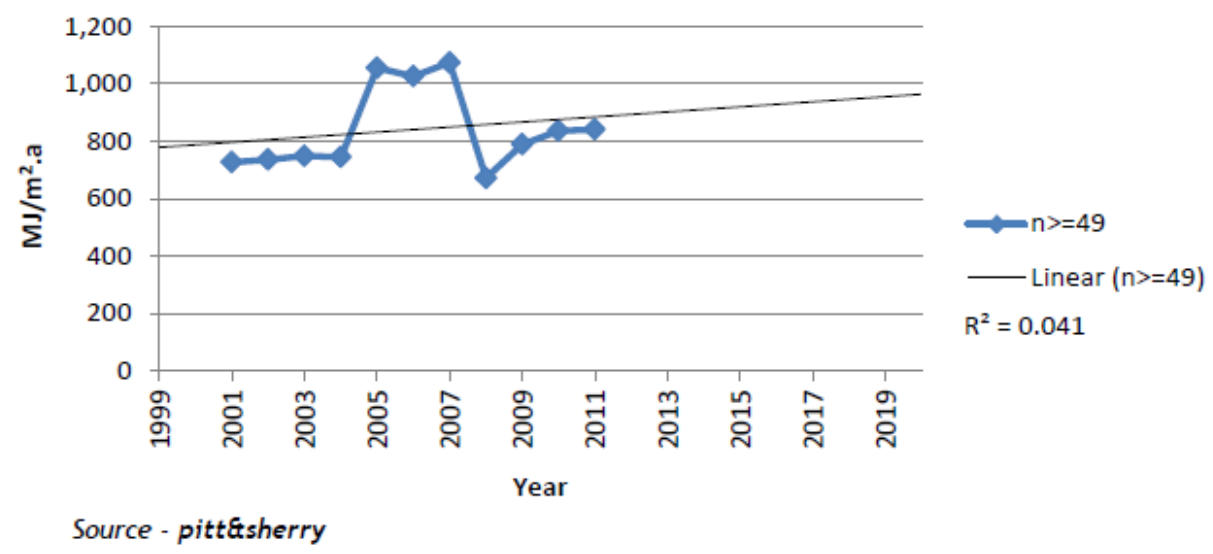

Figure 1 - National average energy intensity of university buildings [3].

The instability in the recorded data is reported to be due to the changes in the categories of rooms occupied as laboratory. As in laboratories, the energy intensity varies very widely based on the type of the laboratory between $10 \mathrm{MJ} / \mathrm{m}^{2}$ and $7,500 \mathrm{MJ} / \mathrm{m}^{2}$. The average electricity end use shares of universities are shown in figure 2 . This breaks down into heating, ventilation and air conditioning (HVAC) that takes about $50 \%$, while lighting stands in the second place in terms of electricity use by $18 \%$ share. 


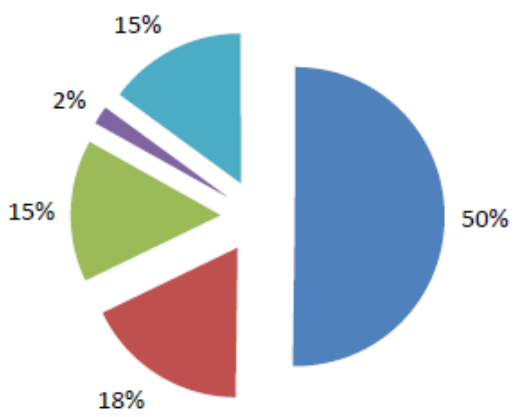

- HVAC

- Lighting

- Total Equipment

Domestic Hot Water

Other electrical process

Source - pittksherry

Figure 2 - Electrical end use shares of Australian universities (1999-2012) [3]

Reports indicate that New South Wales, despite having a less area occupied by the universities, consumes a larger portion of energy compared to Victoria. Table 1 below shows the state's energy consumption. From this table, and in combination with table 2, the relatively low energy efficiency of building in Sydney and Perth can be understood. Despite having smaller area occupied by the tertiary education sector in Sydney and Perth, they both record a higher consumption compared to Melbourne and Brisbane as the capital cities of Victoria and Queens land.

Table 1 - Total energy consumption in university buildings by State [3].

\begin{tabular}{|c|c|c|c|}
\hline (PJ) & 1999 & 2009 & 2020 \\
\hline NSW & 1.3 & 2.3 & 3.5 \\
\hline VIC & 1.1 & 2.1 & 3.2 \\
\hline QLD & 0.8 & 1.3 & 2.0 \\
\hline WA & 0.4 & 0.8 & 1.3 \\
\hline SA & 0.3 & 0.5 & 0.8 \\
\hline TAS & 0.1 & 0.2 & 0.2 \\
\hline ACT & 0.2 & 0.3 & 0.4 \\
\hline NT & 0.1 & 0.1 & 0.1 \\
\hline Total: & 4.3 & 7.7 & 11.6 \\
\hline
\end{tabular}


Table 2 - Estimate of university floor area, 1999-2020, '000m²' [3]

\begin{tabular}{|c|c|c|c|c|c|c|c|c|c|c|c|c|c|c|c|c|c|c|c|c|c|c|}
\hline & 1999 & 2000 & 2001 & 2002 & 2003 & 2004 & 2005 & 2006 & 2007 & 2008 & 2009 & 2010 & 2011 & 2012 & 2013 & 2014 & 2015 & 2016 & 2017 & 2018 & 2019 & 2020 \\
\hline Sydney & 1,157 & 1,157 & 1,300 & 1,385 & 1,436 & 1,416 & 1,404 & 1,465 & 1,548 & 1,664 & 1,858 & 1,970 & 2,077 & 2,128 & 2,178 & 2,231 & 2,284 & 2,338 & 2,394 & 2,451 & 2,510 & 2,570 \\
\hline Other NSW & 486 & 486 & 546 & 612 & 664 & 675 & 690 & 702 & 730 & 765 & 816 & 860 & 895 & 916 & 938 & 959 & 982 & 1,005 & 1,028 & 1,052 & 1,076 & 1,101 \\
\hline Melbourne & 1,171 & 1,171 & 1,316 & 1,404 & 1,469 & 1,524 & 1,535 & 1,595 & 1,720 & 1,835 & 1,998 & 2,110 & 2,222 & 2,275 & 2,329 & 2,383 & 2,440 & 2,497 & 2,556 & 2,616 & 2,678 & 2,741 \\
\hline Other Victoria & 269 & 269 & 302 & 332 & 358 & 378 & 379 & 403 & 437 & 457 & 471 & 483 & 504 & 516 & 528 & 540 & 552 & 565 & 578 & 591 & 605 & 619 \\
\hline Brisbane & 617 & 617 & 693 & 740 & 759 & 763 & 771 & 798 & 836 & 859 & 931 & 1,019 & 1,070 & 1,095 & 1,121 & 1,147 & 1,174 & 1,202 & 1,230 & 1,259 & 1,288 & 1,318 \\
\hline Other Queensland & 348 & 348 & 391 & 411 & 422 & 471 & 555 & 571 & 518 & 506 & 569 & 587 & 616 & 632 & 647 & 662 & 678 & 694 & 711 & 728 & 746 & 764 \\
\hline Perth & 548 & 548 & 616 & 654 & 716 & 734 & 760 & 790 & 811 & 868 & 968 & 1,036 & 1,086 & 1,112 & 1,139 & 1,166 & 1,194 & 1,223 & 1,252 & 1,282 & 1,313 & 1,344 \\
\hline Other WA & 0 & 0 & 0 & 0 & 0 & 0 & 0 & 0 & 0 & 0 & 0 & 0 & 0 & 0 & 0 & 0 & 0 & 0 & 0 & 0 & 0 & 0 \\
\hline Adelaide & 375 & 375 & 421 & 433 & 463 & 491 & 491 & 514 & 548 & 567 & 598 & 626 & 653 & 669 & 684 & 700 & 717 & 733 & 750 & 768 & 786 & 804 \\
\hline Other SA & 1 & 1 & 1 & 1 & 1 & 1 & 1 & 1 & 3 & 4 & 4 & 3 & 0 & 0 & 0 & 0 & 0 & 0 & 0 & 0 & 0 & 0 \\
\hline Hobart & 129 & 129 & 145 & 154 & 156 & 190 & 183 & 183 & 188 & 178 & 179 & 184 & 192 & 196 & 201 & 205 & 210 & 215 & 220 & 225 & 230 & 235 \\
\hline Other Tasmania & 1 & 1 & 1 & 1 & 1 & 1 & 1 & 1 & 3 & 4 & 4 & 3 & 0 & 0 & 0 & 0 & 0 & 0 & 0 & 0 & 0 & 0 \\
\hline ACT & 270 & 270 & 304 & 327 & 355 & 252 & 228 & 228 & 216 & 229 & 356 & 352 & 366 & 375 & 383 & 392 & 401 & 410 & 420 & 429 & 439 & 449 \\
\hline Darwin & 189 & 189 & 212 & 231 & 210 & 139 & 100 & 100 & 82 & 76 & 84 & 78 & 82 & 83 & 85 & 87 & 89 & 91 & 93 & 96 & 98 & 100 \\
\hline Other NT & 0 & 0 & 0 & 0 & 0 & 0 & 0 & 0 & 0 & 0 & 0 & 0 & 0 & 0 & 0 & 0 & 0 & 0 & 0 & 0 & 0 & 0 \\
\hline Aust. & 5,561 & 5,561 & 6,247 & 6,686 & 7,011 & 7,034 & 7,099 & 7,353 & 7,640 & 8,011 & 8,837 & 9,312 & 9,763 & 9,997 & 10,233 & 10,474 & 10,721 & 10,974 & 11,233 & 11,498 & 11,769 & 12,047 \\
\hline
\end{tabular}




\section{Data collection and analysis}

In this part of the study due to the confidentiality reasons the data collection and static analysis are described in general terms only. One of the commercial tertiary buildings located in Sydney business district with a dense urban texture had gone under energy auditing for an 8-year period. The building services and facility management records the energy consumption by electricity counter meters in 15 minutes time intervals. Since 2013 the trend of energy consumption had been recorded. The data ledger consists of 260,419 rows of data including the exact date and time and the recorded electricity consumption for the whole building. The 7-storey building has a parking level accommodating $110 \mathrm{car}$ parks, 3 domestic cold-water pumps, compressor unit to service robotics lab and workshop machineries and a car park ventilation unit. The facility management visualizes the data manually to gain a proper understanding of the trends. Figure 3 shows the electricity consumption in different years since 2013. A notable consumption behaviour that can be observed from this diagram is the significant drop in the in 2020 due to the COVID19. The declining graph in $31^{\text {st }}$ of every month is because of the fact that not all the months have 31 days and thus there will be no records in the majority of the months on this day. A steady and relatively low energy consumption in 2019 had also been recorded. In years 2013 and 2015 the volatility of the energy consumption was considerably high. Volatility of the consumption can be seen as a negative occurrence since it makes the prediction and decision making difficult for the facility management i.e. if one is about to plan for the future in a volatile environment, the accuracy of the prediction is eventually low because of the wide range of possible outcomes.

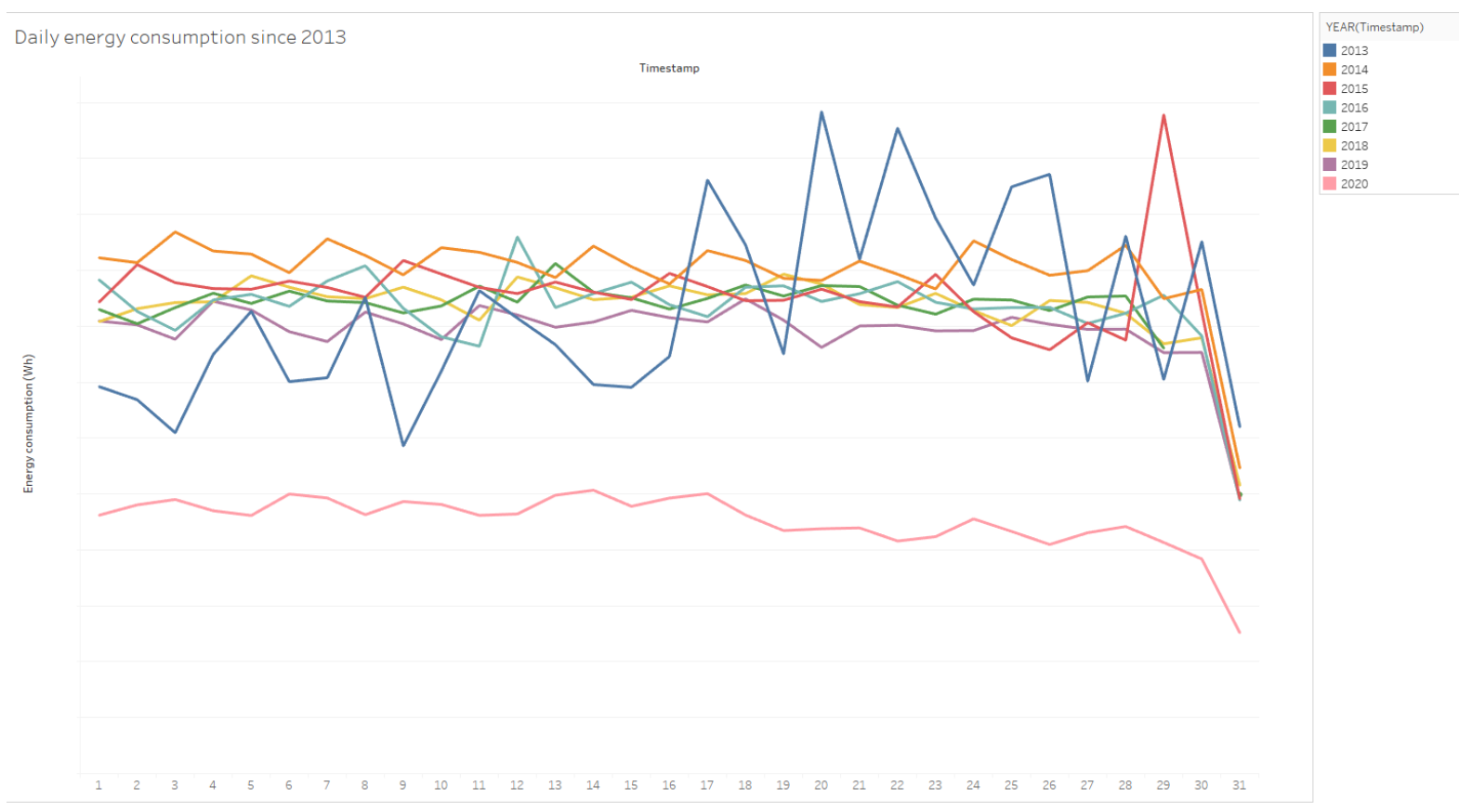

Figure 3 - Daily energy consumption since 2013. 


\section{Dynamic data processing}

The problem with the current workflow is that the data collection and analysis is static. This means that, currently, graphs and visualizations demand a human operator to obtain the data from the sensors, format them in a readable structure for machine (analysis software which in this case was Tableau), and upon a time consuming process at the end, starts visualizing the structured data which then can be interpreted by the user. A better system of data collection and analysis, however, can reduce the time of analysis and reliance on human operators meanwhile increasing the accuracy and accessibility of processed data in the form of usable information.

In that regards, a dynamic data processing system had been designed using electronic sensors. Two separate sensors were used being DHT11 temperature/humidity sensor, and a photoresistor to record the lighting data in a room. A microcontroller facilitates the integration between the hardware and software where the actual data is processed. The circuits configuration for each of the modules are shown in figure 1. Both circuits are operating on $5 \mathrm{~V}$ power source that can be supplied either from a battery or a simple USB input. A notable point in closing the circuit for photoresistor is the requirement for an external resistor. Depending on the resistance of the resistor, the numbers generated by the lighting sensor varies. It is important for calibration purposes as if an end user decides to switch some of the lights ON/OFF based on the number received from the sensor, then the resistance must be considered to set the thresholds.
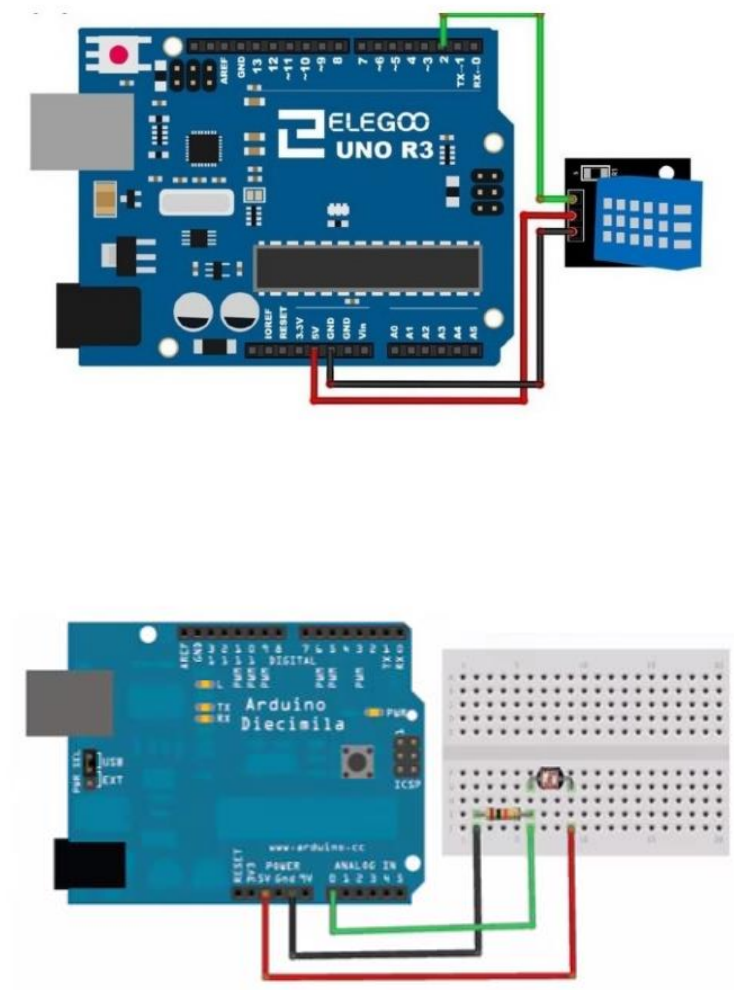

Figure 4-Top: Temperature and humidity sensor circuit setup; Bottom: Photoresistor and microcontroller circuit setup 
Time intervals between each collection can be set in the IDE upon the integration with computer. For building energy consumption purposes, 15 minutes time interval appears logical. Nevertheless, the data is collected and captured by the computer processor after setting up the above circuits. The next step is to format the data received from the sensor into a readable structure. Most of the existing data analysis softwares such as MS Excel ${ }^{\circledR}$ and Tableau ${ }^{\circledR}$ are compatible with CSV file (Comma Separated Values). Thus, a CSV converter had been set between the serial port (from the microcontroller) and MS Excel. Data is now poured in the system and analysed instantaneously.

The code snippets for environmental sensors are given below.

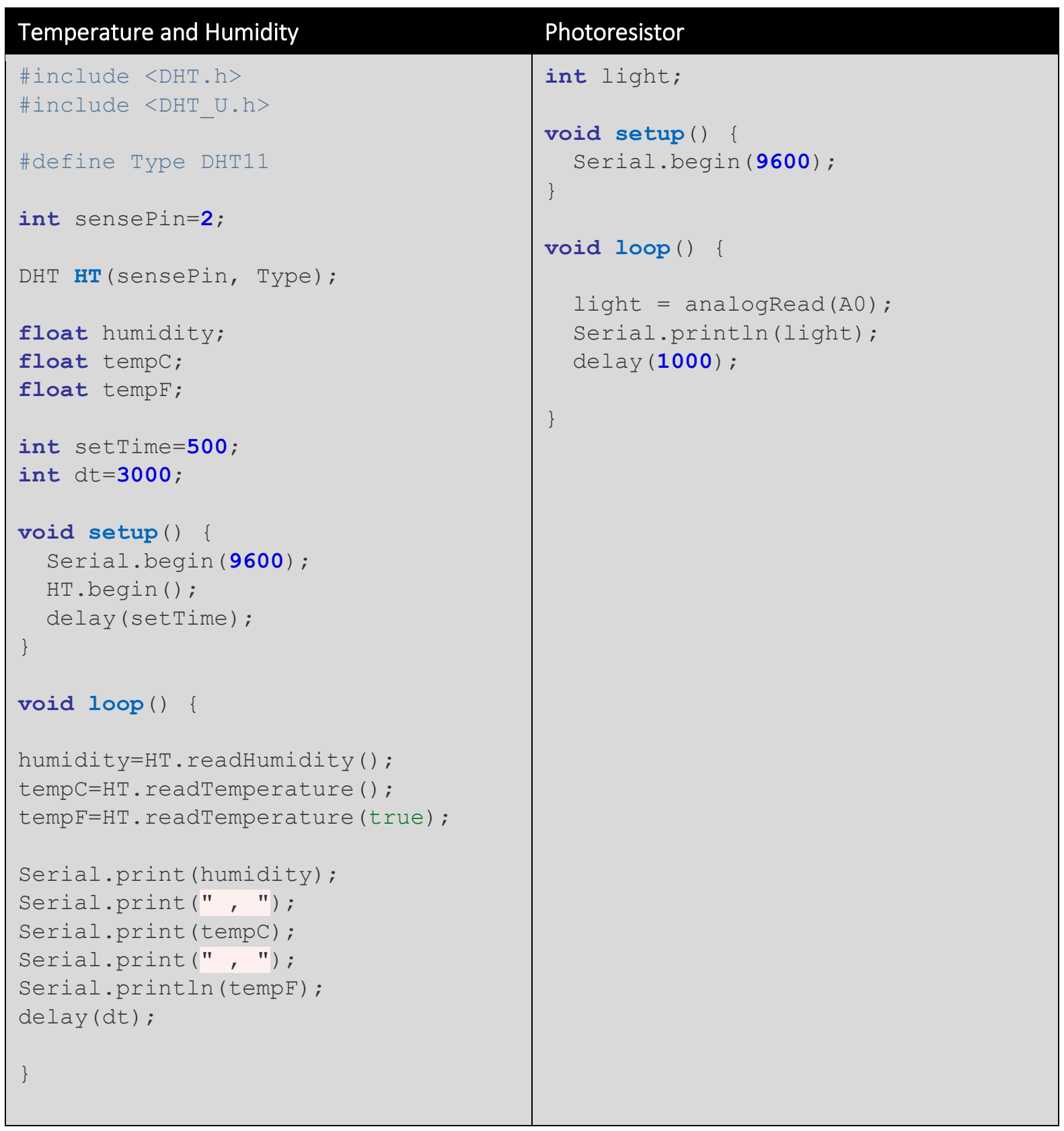

The next step towards commercialization of this environmentally friendly module is the optimum circuit design by soldering which can then be placed in a 3D printed shield. The 3D design of the shield is 
typically done using Fusion $360^{\mathrm{TM}}$ depending on the dimensions of the circuit. The required output file format is often. SLT which is further in the next step must be converted into a G-Code file format compatible with the printer input. It is also recommended to use PLA (Polylactic Acid) filaments which itself is made through a recycling process; adding to the environmental values of the introduced module. PLA is a widely used bioplastic due to it being economically produced from renewable resources [10].

Furthermore, by adding wireless communication transceiver ESP8266 to the circuit. In this way, the humidity, temperature, and lighting sensors can be installed anywhere in the building within a 100meter distance from the wireless router. The central computer will then collect and send relevant information to and from the sensors. Overall, the circuit design and programming procedures introduced in this article, can be adopted in many other areas of environmental construction and building design such as $\mathrm{CO}_{2}$ Concrete [11-17], Graphene production [18, 19], and most effectively in the managerial aspects of construction [20-28] where data science plays a crucial role.

\section{Acknowledgement}

The contributions from the Institute of Construction Materials had shed light on the alignment of this research. This study had been conducted to first raise awareness about the status quo of building energy consumption in Australia, and then, to introduce effective technologies for reducing the level of electricity consumption which ultimately leads to the wellbeing and sustainability of our modern urban environment. Thus, it is unlikely to raise any conflict of interest.

\section{Conclusion}

Amid the global population growth and the increasing need for sustainable energy supplies, this study had evaluated the energy consumption of commercial buildings in Australia. The concept of smart building was taken as foundation to the rest of the study i.e. utilization of digital instruments for monitoring the energy consumption had been tested. Following a preliminary static analysis on the data obtained from a commercial building in Sydney, this study had then introduced a dynamic method of data collection and analysis which allows instantaneous data visualization and gives the end user the ability to make decision on-demand. The outcomes are beneficial particularly to building facility management. A more advanced version of the dynamic system introduced is capable of controlling temperature, humidity, and lighting based on the responses received from the occupants with minimum human intervention. 


\section{References}

[1] M. Bourdeau, X. qiang Zhai, E. Nefzaoui, X. Guo, and P. Chatellier, "Modeling and forecasting building energy consumption: A review of data-driven techniques," Sustainable Cities and Society, vol. 48, p. 101533, 2019.

[2] O. G. Santin, "Occupant behaviour in energy efficient dwellings: evidence of a rebound effect," Journal of Housing and the Built Environment, vol. 28, no. 2, pp. 311-327, 2013.

[3] "Baseline Energy Consumption and Greenhouse Gas Emissions in Commercial Buildings in Australia," Department of Climate Change and Energy Efficiency 2012.

[4] S. Fathi, R. S. Srinivasan, C. J. Kibert, R. L. Steiner, and E. Demirezen, "Al-Based Campus Energy Use Prediction for Assessing the Effects of Climate Change," Sustainability, vol. 12, no. 8, p. 3223, 2020.

[5] B. B. Ekici and U. T. Aksoy, "Prediction of building energy consumption by using artificial neural networks," Advances in Engineering Software, vol. 40, no. 5, pp. 356-362, 2009.

[6] Y. Agarwal, T. Weng, and R. K. Gupta, "The energy dashboard: improving the visibility of energy consumption at a campus-wide scale," in Proceedings of the First ACM Workshop on Embedded Sensing Systems for Energy-Efficiency in Buildings, 2009, pp. 55-60.

[7] O. Bates and A. Friday, "Beyond data in the smart city: repurposing existing campus IoT," IEEE Pervasive Computing, vol. 16, no. 2, pp. 54-60, 2017.

[8] C. Wei and Y. Li, "Design of energy consumption monitoring and energy-saving management system of intelligent building based on the Internet of things," in 2011 international conference on electronics, communications and control (ICECC), 2011: IEEE, pp. 3650-3652.

[9] L. Linder, D. Vionnet, J.-P. Bacher, and J. Hennebert, "Big Building Data-a big data platform for smart buildings," Energy Procedia, vol. 122, pp. 589-594, 2017.

[10] V. Nagarajan, A. K. Mohanty, and M. Misra, "Perspective on polylactic acid (PLA) based sustainable materials for durable applications: Focus on toughness and heat resistance," ACS Sustainable Chemistry \& Engineering, vol. 4, no. 6, pp. 2899-2916, 2016.

[11] A. Todhunter, M. Crowley, M. Gholamisheverini, and F. Sartipi, "Advanced technological implementation of construction and demolition waste recycling," Journal of Construction Materials, vol. 1, no. 1, 2019, doi: https://doi.org/10.36756/JCM.v1.1.3.

[12] F. Sartipi, "Automatic sorting of recycled aggregate using image processing and object detection," Journal of Construction Materials, vol. 1, pp. 3-3, 2020, doi: https://doi.org/10.36756/JCM.v1.2.1.

[13] F. Sartipi, "A brief critical view on the carbon-conditioning of recycled aggregate using pressure chamber," Journal of Construction Materials, vol. 2, pp. 1-4, 2020, doi: https://doi.org/10.36756/JCM.v2.1.4.

[14] A. Gharizadeh, F. Sartipi, E. Ayoubi, and A. Severino, "The chemical reactor design configuration of $\mathrm{CO} 2$ concrete green solution," Journal of Construction Materials, vol. 1, pp. 25, 2020, doi: https://doi.org/10.36756/JCM.v1.2.5.

[15] J. Luliano, A. Singh, and F. Sartipi, "Political-economical evaluation of CO2 capture in Australian building sector," Journal of Construction Materials, vol. 1, pp. 3-2, 2020, doi: https://doi.org/10.36756/JCM.v1.3.2.

[16] M. Sartipi and F. Sartipi, "Stormwater retention using pervious concrete pavement: Great Western Sydney case study," Case Studies in Construction Materials, vol. 11, p. e00274, 2019.

[17] A. Todhunter, M. Crowley, F. Sartipi, and K. Jegendran, "Use of the by-products of postcombustion carbon capture in concrete production: Australian case study," Journal of Construction Materials, vol. 1, no. 1, 2019, doi: https://doi.org/10.36756/JCM.v1.1.1.

[18] F. Sartipi, A. Ghari Zadeh, and M. Gamil, "Electrical resistance of graphene reinforced cement paste," Journal of Construction Materials, 2019.

[19] M. Gamil, A. Ghari Zadeh, and F. Sartipi, "A review on graphene reinforced cement composite: technical approach for ecofriendly construction," Journal of Construction Materials, 2019. 
[20] T. Boulos, F. Sartipi, and K. Khoshaba, "Bibliometric analysis on the status quo of robotics in construction," Journal of Construction Materials, vol. 1, pp. 2-3, 2020.

[21] F. Sartipi and A. Sartipi, "Brief review on advancements in construction additive manufacturing," Journal of Construction Materials, vol. 1, pp. 2-4, 2020, doi: https://doi.org/10.36756/JCM.v1.2.4

[22] A. Todhunter, M. Crowley, and F. Sartipi, "Construction productivity indices in socialism compared with capitalism," Journal of Construction Materials, 2019, doi: https://doi.org/10.36756/JCM.v1.1.2.

[23] F. Sartipi, "Diffusion of Innovation Theory in the Realm of Environmental Construction," Journal of Construction Materials, vol. 1, pp. 4-2, 2020, doi: https://doi.org/10.36756/JCM.v1.3.2.

[24] V. Tam, F. Sartipi, and K. N. Le, "Gaps between supply and demand of recycled aggregate: Sydney metropolitan case study," Presented at the CRIOCM 2018, 2018.

[25] F. Sartipi, "Influence of $5 \mathrm{G}$ and IoT in construction and demolition waste recycling-conceptual smart city design," Journal of Construction Materials, vol. 1, pp. 4-1, 2020, doi: https://doi.org/10.36756/JCM.v1.4.1.

[26] F. Sartipi, "Organizational structure of construction entities based on the cooperative game theory," Journal of Construction Materials, vol. 1, no. 2, 2020, doi: https://doi.org/10.36756/JCM.v1.3.3

[27] F. Sartipi and M. Soomro, "Solutions for barriers against the wider use of recycled aggregate."

[28] F. Sartipi, K. Palaskar, A. Ergin, and U. Rajakaruna, "Viable construction technology for habitation on Mars: Fused Deposition Modelling," Journal of Construction Materials, vol. 1, no. 2, 2020. 